\title{
A tactical way to support the long-term mining plans production capacities
}

\author{
J.M. Castro Codelco, Chile \\ M. Larraín Codelco, Chile
}

\section{Abstract}

The common practice of the medium-and long-term mine planning is to set the production plans in terms of the maximal Net Present Value (NPV) as a target by the use of optimisation software packages. These computational tools use simplistic representations of the whole productive system as a flow network expressed on a yearly basis. As such, these tools require of technical parameters related to production capacity and flexibilities of the different processes, for example, energy consumption considerations of the crushing and milling processes, and the use of availability and utilisation factors as a maintenance programme effects estimation. Therefore, when relatively short stockpiles exist between mine haulage, crushing and milling processes with respect to the whole system capacity, the mine and metallurgical planning requires to be supported by a more detailed and systemic analysis of these processes.

This paper reports on the tactical way El Teniente Mine estimates its strategic bottleneck process capacity. This approach integrates the Teniente 8 rail haulage system and Colón processing plant production plans with the critical equipments maintenance programme and existing stockpiles effect into the whole system production capacity.

\section{Introduction}

El Teniente Mine is a high-tonnage underground copper mine located in Chile, close to Rancagua city. The strategic Business and Development Plan (PND) lists the basic requirements of the production plans for the different mines and processes using a mixed integer-linear programming (MILP) optimisation model (Caro et al., 2007) like other mining companies (Trout, 2005). Therefore the operational features, and variety and complexity of the productive process, the Ferrocarril Teniente 8 haulage system requires an integrated and detailed analysis to estimate the production capacity of the overall mine productive system (Castro et al., 2008). Currently, all these requirements are assessed by the use of simulation like other complex underground operations (Botha et al., 2008).

After the last mine-plant expansion (Proyecto Desarrollo Teniente) implemented in 2005, the El Teniente Mine reached an ore production rate close to big open pit operations but without their stockpiling facilities. The underground mine has a limited stockpiling capacity at the ore pass. This is related to the difficulties to assure the stability of large excavations in the high stress rockmass conditions.

The Colón crushing plant has the same stockpiling limitations related to its location at 1,980 $\mathrm{m}$ above sea level in the Andes Mountains, surrounded by cliffs with difficult access to its railway facilities at the discharge zone. Any critical equipment detention could mean a reduction of the whole system capacity performance as a one-line process.

According to these conditions, mine planning must assess the effect of these stockpiling limitations on the mine-plant integrated process capacity as this process represents the strategic bottleneck of the productive system. This means that a detailed maintenance plan analysis of the different critical equipment (crushers, mills, conveyor belts) is required. 
This work aims to show the analysis that supports the current mine planning approach used to integrate the Teniente 8 rail haulage system and Colón processing plant production plans, with the critical equipment maintenance programme and existing stockpiles effect on the whole system production capacity.

\section{System description}

A general view of the Colón processing plant facilities is provided in Figure 1. The first process is the rail system. This system carries out the ore from the underground mine to the primary crushing bin by trains with coarse ore size cars (run-of-mine ore under $1 \mathrm{~m}$ size) to the secondary crushing bin by the use of trains with fine ore size cars (in-mine crushed ore under $0.3 \mathrm{~m}$ size). The fine ore cars can discharge to both bins, but the coarse ore cars can only discharge to the primary crushing bin. The design parameters of the railroad equipment are shown in Table 1.

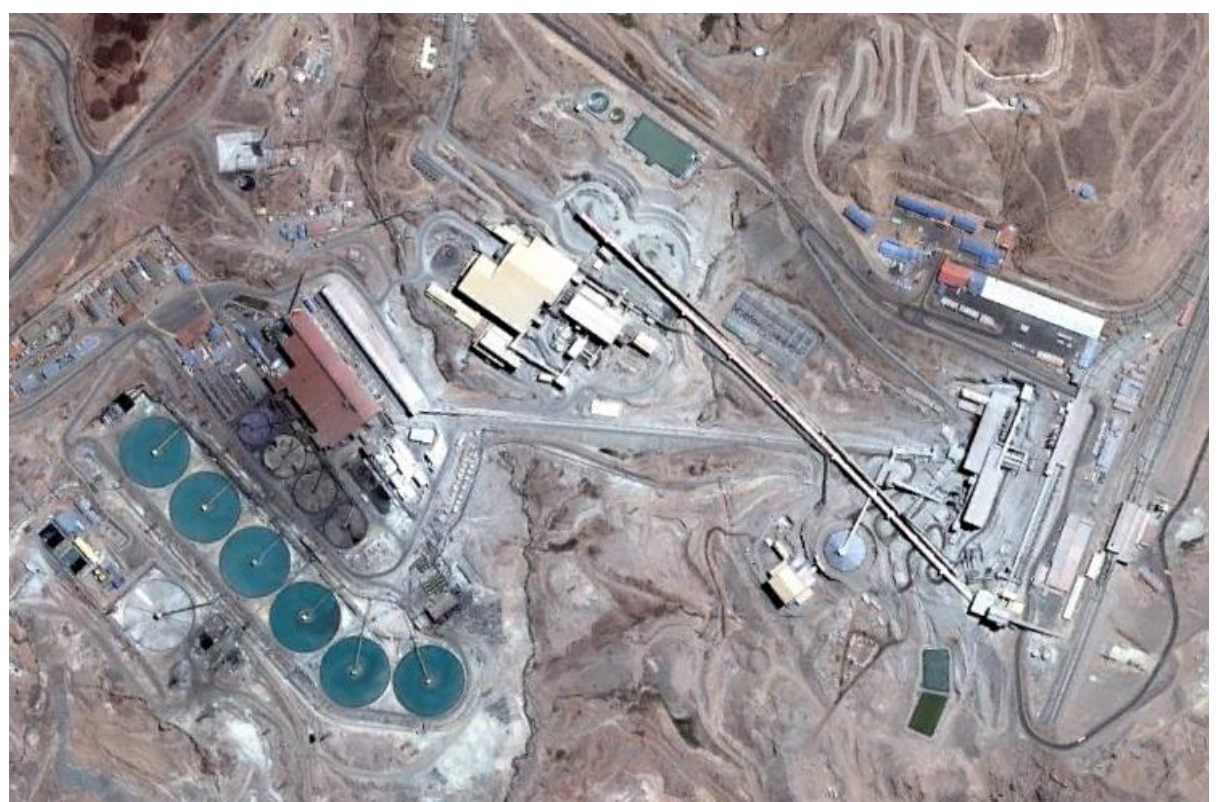

Figure 1 General view of the productive system (source: Google Earth)

This is followed by the primary crushing process and the transference tower. The tower facilitates distribution of the crushed ore to the SAG-1 grinding circuit stockpile, SAG-2 grinding circuit stockpile and the secondary crushing bin according to the whole grinding process requirements. The secondary and tertiary crushing process follows the ball mill circuit section 1-12 and section 13 stockpiles. This crushing process must supply both stockpiles according to the whole ball mills circuit requirements. Following the milling processes, is the final, frothing concentration process.

Table 1 General description of the rail equipment

\begin{tabular}{llll}
\hline Process & Equipment & Features & Comments \\
\hline Coarse ore trains & $130 \mathrm{t}$ Schalke locos & $\begin{array}{l}\text { Power: } 1.600[\mathrm{HP}] ; \text { max. } \\
\text { speed } 60[\mathrm{Km} / \mathrm{h}]\end{array}$ & 5 trains \\
& $48 \mathrm{t}$ cars & $\begin{array}{l}80 \mathrm{t} \text { capacity; max. ore size } \\
1 \mathrm{~m} \text {; lateral discharge }\end{array}$ & 19 cars per train \\
& & $\begin{array}{l}\text { Power: } 1.600[\mathrm{HP}] ; \text { max. } \\
\text { speed } 60[\mathrm{Km} / \mathrm{h}]\end{array}$ & 2 trains \\
& $130 \mathrm{t}$ Schalke locos & \\
& $38 \mathrm{t}$ cars & $0.5 \mathrm{t}$; capacity; max. ore size & 19 cars per train \\
& & & \\
\hline
\end{tabular}


The design parameters of the main crushing and grinding equipment are shown in Table 2 and the bin and stockpile capacities are shown in Table 3.

Table 2 General description of the crushing and grinding equipment

\begin{tabular}{llll}
\hline Process & Equipment & Dimensions & Power [HP] \\
\hline Primary crushing & Giratory crusher N ${ }^{\circ} 1$ & $1.35 \times 1.85 \mathrm{~m}$ & 500 \\
& Giratory crusher N ${ }^{\circ}$ & $1.5 \times 2.2 \mathrm{~m}$ & 800 \\
Sec. and ter. crushing & Sec. cone crushers H8800 & - & $3 \times 800$ \\
& Ter. cone crushers H8800 & - & $6 \times 800$ \\
& Ter. cone crushers symons 7SH & - & $2 \times 350$ \\
SAG-1 grinding & SAG-1 mill & $10.8 \times 4.5 \mathrm{~m}$ & 15,000 \\
& Ball mills & $8.4 \times 5.4 \mathrm{~m}$ & $2 \times 6,000$ \\
SAG-2 grinding & SAG-2 mill & $11.4 \times 6 \mathrm{~m}$ & 26,000 \\
& Ball mills & $7.2 \times 10.8 \mathrm{~m}$ & $2 \times 15,000$ \\
Ball mills (1-12) & Hardinge mills & $4.2 \times 7.2 \mathrm{~m}$ & $7 \times 2,500$ \\
& Hardinge mills & $4.2 \times 7.2 \mathrm{~m}$ & $1 \times 3,500$ \\
& Fuller ball mills & $4.2 \times 7.2 \mathrm{~m}$ & $4 \times 3,800$ \\
Ball mill (13) & - & $7.2 \times 10.8 \mathrm{~m}$ & 15,000 \\
\hline
\end{tabular}

Table 3 Capacities of the main bins and stockpiles

\begin{tabular}{ll}
\hline Item & Live Capacity [t] \\
\hline Primary crushing bins & $2 \times 4,000$ \\
SAG-1 stockpile & 25,000 \\
SAG-2 stockpile & 50,000 \\
Secondary crushing bins & $1 \times 8,000$ \\
& $1 \times 4,000$ \\
Ball mills (1-12) & 20,000 \\
Ball mill (13) & 5,600 \\
\hline
\end{tabular}

\section{$3 \quad$ Modelling}

\section{1 Formulation}

The proposed mathematical model of the whole system production capacity is a linear programming model and its features are described in the following paragraphs.

The objective function is to maximise the whole tonnage processed in the evaluation period, as shown in Equation (1).

$$
T O N=\sum_{t=1}^{T} \sum_{i=1}^{I} P_{i, t}
$$


where:

TON = total processed tonnage, $\mathrm{t}$.

$P_{i, t}=\quad$ production processed in the line $\mathrm{i}$ at period $\mathrm{t}, \mathrm{t}$.

This problem is subject to the mass balance constraints and technical constraints that define the feasible solutions. The mass balance constraints can be classified as equipment flow balance (Equation (2)) and bins/stockpiling balance (Equation (3)).

$$
\sum P_{j, t}^{I N}=\sum P_{j, t}^{\text {OUT }}
$$

$$
\forall j, t
$$

where:

$P_{j, t}^{{ }^{I N}}=$ production supplied to the line $\mathrm{j}$ at period $\mathrm{t}, \mathrm{t}$.
$P_{j, t}^{\text {OUT }}=$ production processed in the line $\mathrm{j}$ at period $\mathrm{t}, \mathrm{t}$.

$$
S_{j, t}=S_{j, t-1}+\sum P_{j, t}^{I N}-\sum P_{j, t}^{\text {OUT }} \quad \forall j, t
$$

where:

$S_{j, t}$ $=\quad$ stock of material in line $\mathrm{j}$ at period $\mathrm{t}, \mathrm{t}$.

The technical constraints can be classified as maximal design equipment capacities by energy/power considerations and the minimal capacities in accordance with operational considerations, as shown in Equation (4).

$$
P_{j, t}^{M I N} \leq P_{j, t} \leq P_{j, t}^{M A X}
$$$$
\forall j, t
$$

where:

$P_{j, t}{ }^{M I N}=$ minimal production capacity of the line $\mathrm{j}$ at period $\mathrm{t}, \mathrm{t}$.
$P_{j, t}{ }^{M A X}=$ maximal production capacity of the line $\mathrm{j}$ at period $\mathrm{t}, \mathrm{t}$.

The maximal design equipment capacities are estimated by Equation (5) for the ball mills, according to the Bond's model and Equation (6) for the SAG mills.

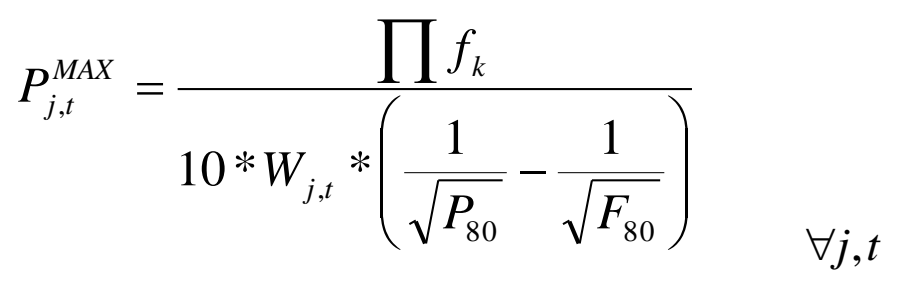

where:

$$
\begin{aligned}
& f_{k} \quad=\quad \text { modification factors of the Bond's model. } \\
& W_{j, t} \quad=\quad \text { Work index (Bond's model) of the ore supplied to the line } \mathrm{j} \text { at period } \mathrm{t}, \mathrm{KWh} / \mathrm{tc} .
\end{aligned}
$$


$P_{80}=\quad=80 \%$ ore size passing product, microns.

$F_{80}=80 \%$ ore size passing feed, microns.

$$
P_{j, t}^{M A X}=\frac{24 * P * U * T_{e}}{\left(E_{p} * f_{e s c}\right)}
$$

where:

$P$

$=\quad$ electric power of the SAG grinding circuit, $\mathrm{KWh} / \mathrm{t}$.

$U$

$=\quad$ SAG grinding circuit utilisation, $\%$.

$T_{e} \quad=\quad$ SAG grinding circuit type, as fraction.

$E_{p} \quad=\quad$ ore specific energy consumption, $\mathrm{KWh} / \mathrm{t}$.

$f_{\text {esc }}=$ scale factors for the SAG grinding circuit pilot plant test to industrial plant.

The SAG grinding circuits consider the minimum capacity of each SAG mill and ball mills circuit.

The last consideration is the maintenance programme of the critical equipment (mills, crushers, conveyor belts) according to the production requirements.

\section{2 Model solution}

The mathematical model consists of a linear programming model and it is coded and solved in the LP Solve optimisation package software using AMPL (A Mathematical Programming Language). The model has been set to support a short-term production plan, i.e. a one-year period at different timeframes: daily, weekly and monthly.

The haulage capacity is provided by the current simulator of the Teniente 8 rail operation and the crushing and grinding process capacities are provided by internal studies of these processes. The maintenance programme of these processes is set according to the standard annual programme provided by the operations maintenance team.

\section{$4 \quad$ Results}

\section{1 Teniente 8 haulage capacity}

The first step of this analysis is the Teniente 8 haulage capacity assessment. Currently, this system is assessed using a discrete event simulation software and multiple replicants of a Montecarlo simulation. For the purpose of this study, it was necessary to estimate a deterministic and representative value of the system's capacity.

Figure 2 shows the daily production of a one-year simulation of the Teniente 8 haulage system in current conditions. This result shows values between 111 and $151 \mathrm{kt} / \mathrm{d}, 131 \mathrm{kt} / \mathrm{d}$ as average and $135 \mathrm{kt} / \mathrm{d}$ as most frequent value. 


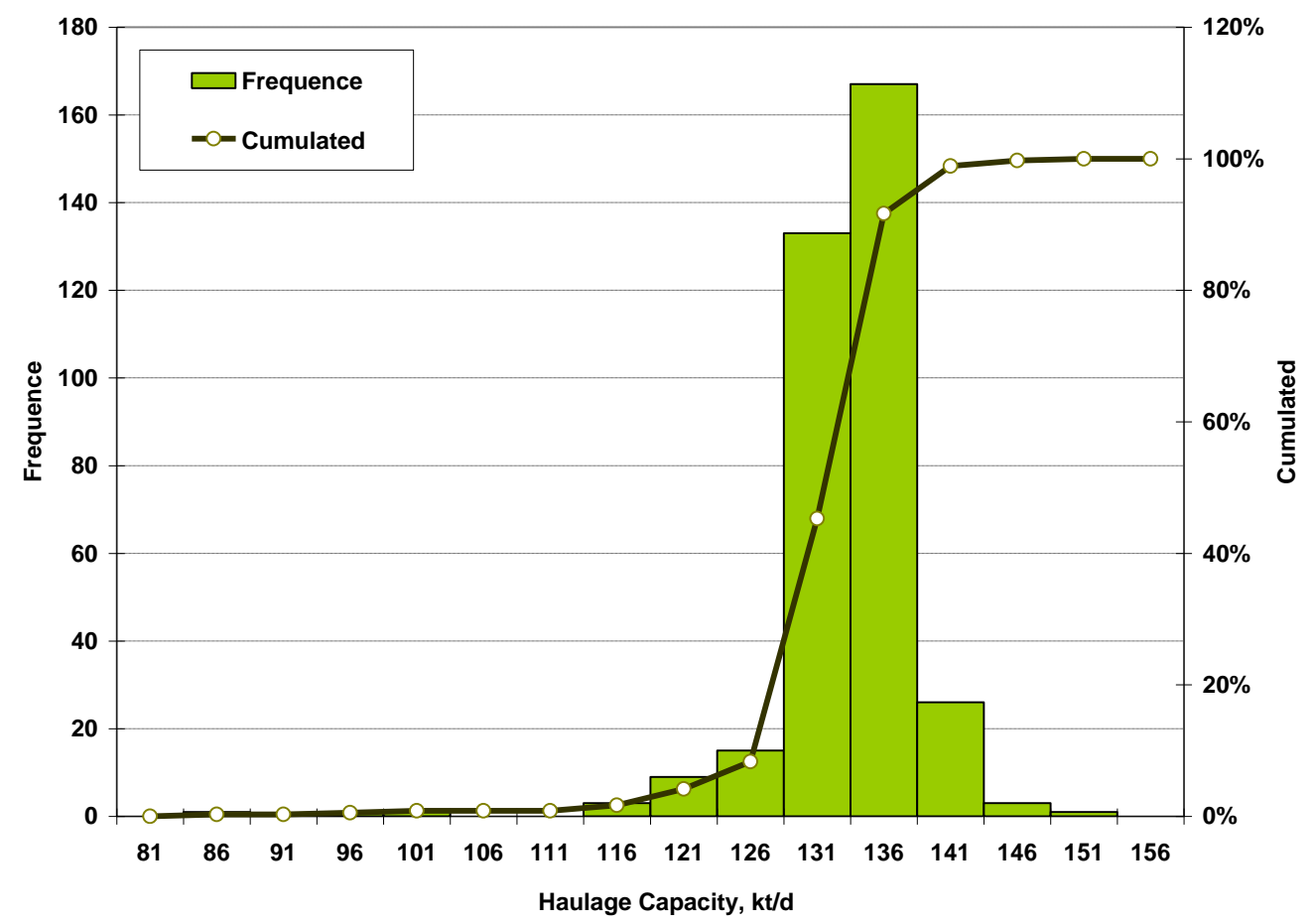

Figure 2 Simulation of one-year Teniente 8 haulage capacity

On the other hand, the haulage capacity was estimated using a different deterministic approach (without random simulation). The result was $135 \mathrm{kt} / \mathrm{d}$, equivalent to the most frequent value according to the simulation results. Nevertheless, this deterministic assessment estimates the hourly performance of the rails during a one-day operation and compares it with the grinding process hourly performance as shown in Figure 3.

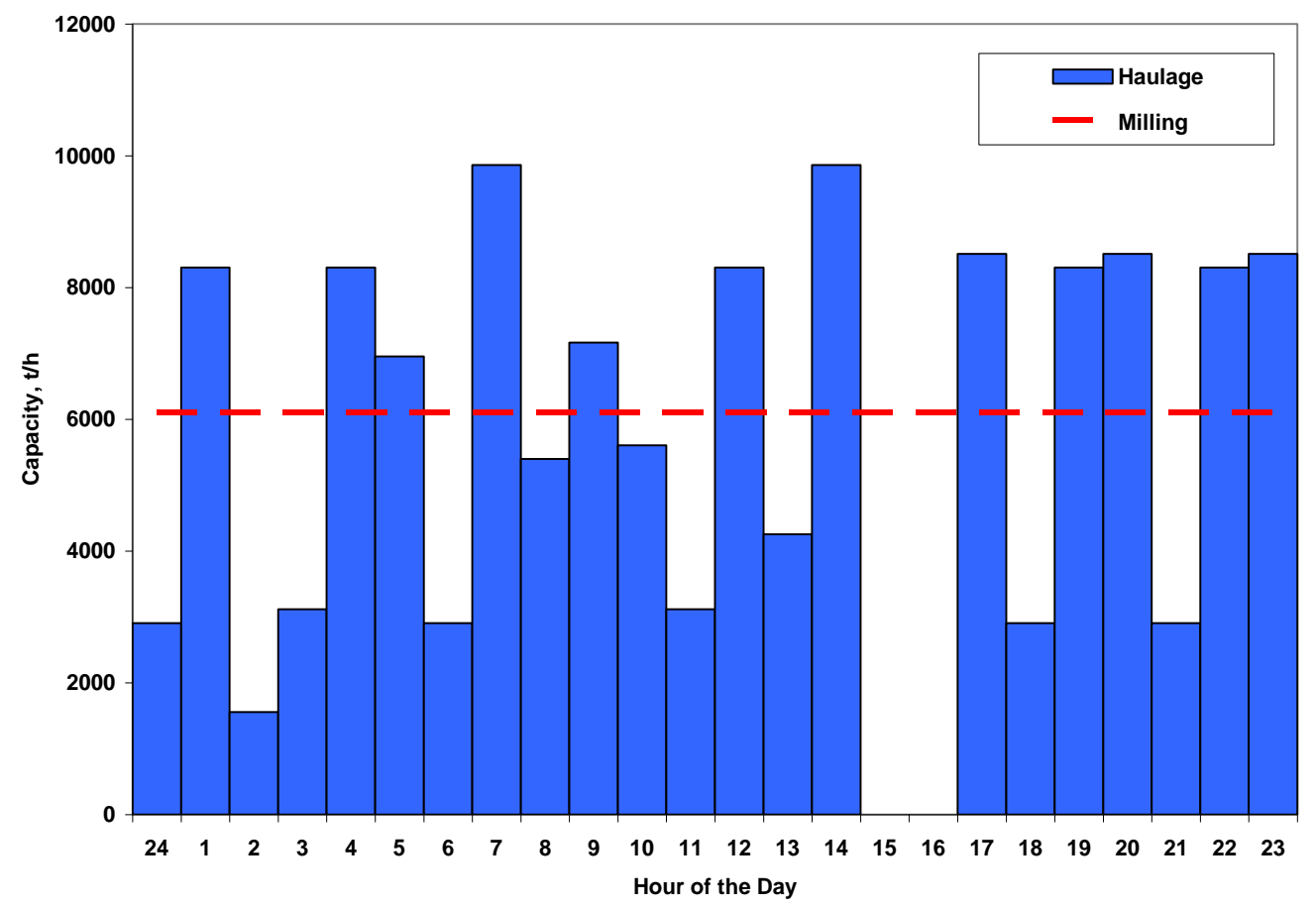

Figure 3 Comparison between the hourly haulage and grinding capacity

Figure 3 shows a comparison between the hourly haulage and grinding capacity. On one hand, the haulage shows a variable capacity during the day mainly caused by the average cycle of the trains (close to 1.5 hours 
per cycle), the effect of the mine operations work system ( 3 shifts, 8 hours duration per day) and the daily railway maintenance (14:00 to $16: 00 \mathrm{~h})$. On the other hand, the grinding shows a stable capacity only affected by changes in the ore size distribution and ore hardness (both considered fixed in this analysis). The other parameter affecting the grinding capacity is related to the maintenance of the critical grinding equipment.

In relation to the difference between the haulage and grinding hourly capacity, it is necessary to manage the stockpiles in the standard operation of the whole process. The effect of the crushing and grinding process maintenance programme will be assessed for a one-year period.

\section{2 Integrated system capacity}

The following analysis of the haulage and processing plant production capacity considers two main issues: the stockpile management strategy analysis and the timeframe analysis.

For the stockpile management strategy analysis, we assess different objective functions, hence the model was set to assess three different scenarios. Option 1: maximise the crushing system output; Option 2: maximise the milling system output; and Option 3: maximise the sum of the crushing and milling output. The purpose of this analysis is to find the operational criteria that maximise the whole system capacity in different timeframe schedules. The results are shown in the Figure 4.

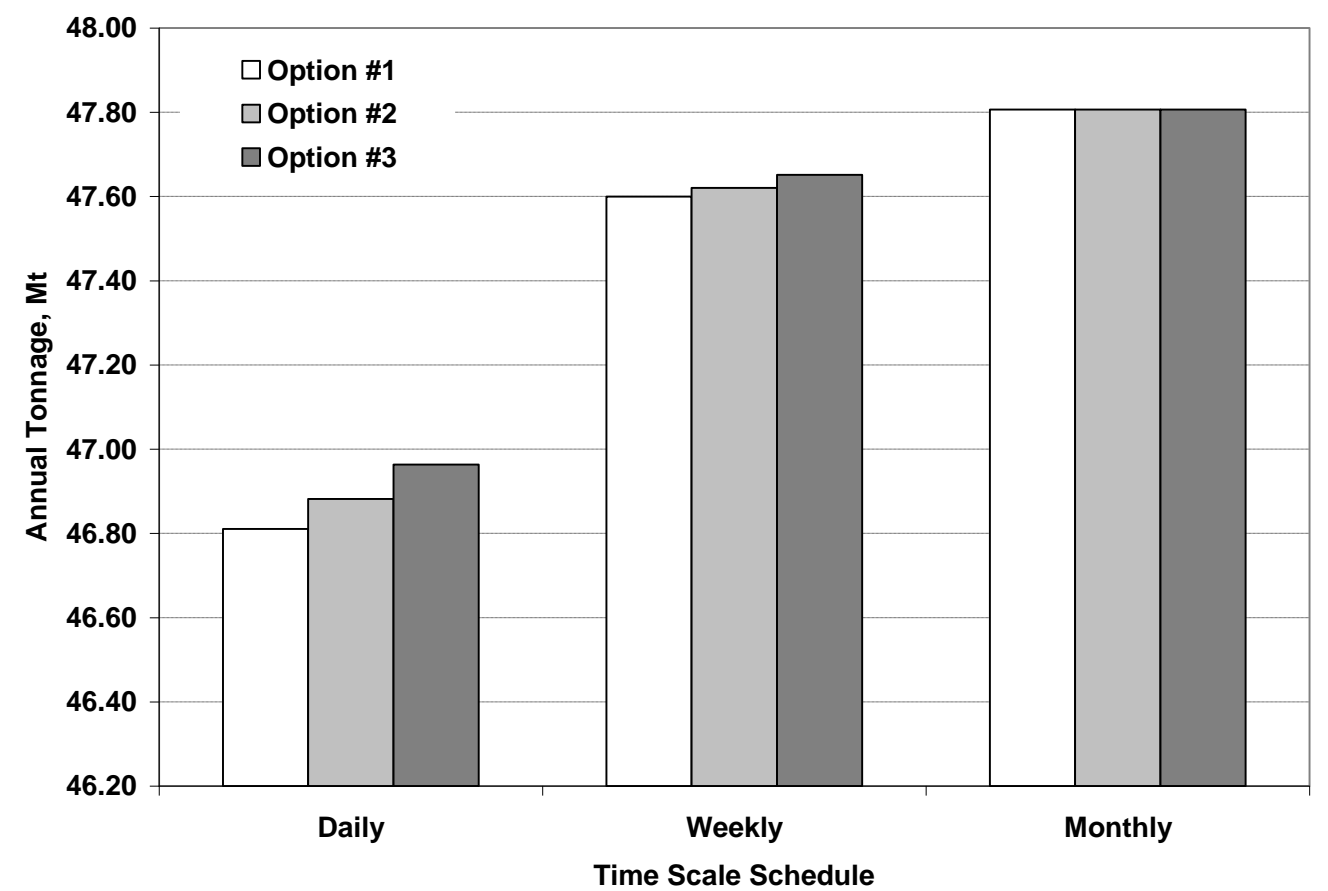

Figure 4 0bjective function analysis results for different timeframe schedules

According to the results shown in Figure 4, Option 3 maximises the whole production capacity for all timeframe schedules assessed which presents a better stockpile management alternative. In other words, the broader the timeframe schedule, the lower the benefit of the stockpile management given the daily timeframe schedule shows a value $1.8 \%$ lower than the monthly one (almost $1 \mathrm{Mt}$ per year). 


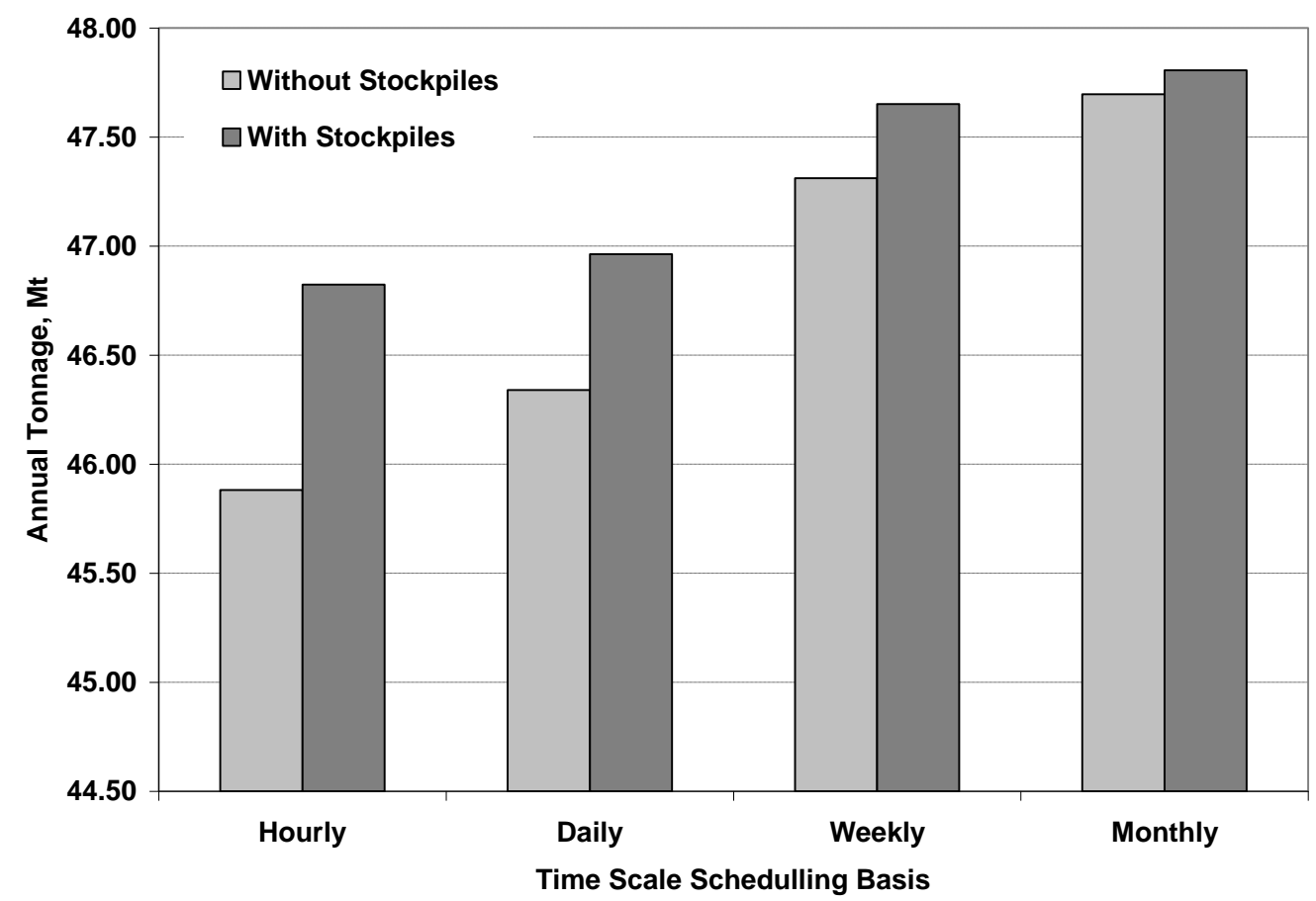

Figure 5 Different timeframe schedules results and stockpiling effect

Figure 5 shows the analysis of the different timeframe schedules and the stockpiling management effect considering the use of Option 3 strategy. As in the previous result, the lower the timeframe schedule, the lower the production capacity. Although for an hourly timeframe schedule, which represents the most detailed feasible one, the result is very close to the daily timeframe with stockpiling management. This result is caused for the stockpiling capacity, which is close to one-day operation capacity of the whole process, and for this reason, a more detailed schedule does not reduce the estimation of the process capacity.

\section{Conclusions}

In summary, the Teniente 8 haulage and Colón plant are the strategic bottleneck of the El Teniente Mine in the long-term. Additionally, given their limited stockpiling facilities, the production plans must also consider a more detailed analysis of their processes as an integrated system.

The Teniente 8 haulage system is analysed using a deterministic approach to obtain a representative and comprehensive capacity estimation, instead of the standard simulation analysis of this process. By doing this, we can understand the stockpiling management required in the daily operation of the Colón plant.

The integrated Teniente 8 and Colón plant system was analysed for a one-year period, taking into account the maintenance programme of the critical equipment of both the processes and different timeframe schedules using the same data. The results show the necessity of at least a daily timeframe scheduling of the whole process given the limited stockpiling capacity of the system, close to a one-day operation. A monthly timeframe schedule overestimates the capacity of the system by $1.8 \%$ (1 Mt per year) in comparison with a daily schedule.

\section{Acknow ledgements}

The authors sincerely thank their colleagues of El Teniente Mine who helped to develop this work. Also, the authors gratefully acknowledge the permission granted by Codelco Chile to publish this technical paper. 


\section{References}

Botha, J., Watson, S., Arkadius, T. and Samosir, E. (2008) Simulation applications at PT Freeport Indonesia's DOZ/ESZ block cave mine, in Proceedings 5th International Conference and Exhibition on Mass Mining, MassMin 2008, H. Schunnesson and E. Nordlund (eds), 9-11 June 2008, Luleå, Sweden, Luleå University of Technology Press, Luleå, pp. 245-252.

Caro, F., Catalán, J., Epstein, R., Goic, M., Santibañez, P. and Weintraub, A. (2007) Long term optimisation of investment and production plans in open-pit and underground copper mines, in Proceedings 33rd APCOM Symposium, Santiago, Chile, pp. 351-358.

Castro, J., Henriquez, J. and San Martín, J. (2008) Simulation model of Ferrocarril Teniente 8 haulage system, El Teniente Mine, in Proceedings 1st International Congress on Automation in Mining Industry AUTOMINING, Santiago, Chile.

Trout, L.P. (2005) Underground Mine Production Scheduling Using Mixed Integer Programming, 25th APCOM Conference, Brisbane, Australia, pp. 395-400. 
